\title{
EDWARD VERMILYE HUNTINGTON 1874-1952
}

Edward Vermilye Huntington was born in Clinton, New York, on April 26, 1874. He was graduated from Harvard University in the class of 1895 , a class which numbered among its members two other mathematicians, J. L. Coolidge and J. K. Whittemore. Two years later he received the A.M. degree from Harvard, serving also as Instructor in Mathematics during those two years. Two years followed at Williams College as instructor in mathematics. 1899 to 1901 were spent in study in Europe, culminating in the Ph.D. degree from Strassburg, on a topic dealing with the foundations of the number systems, thus foreshadowing the field of his later major interest. $\mathrm{He}$ returned to Harvard, where he remained until his retirement in 1941, passing through the then conventional stages of advancement until his appointment in 1919 as Professor of Mechanics under the Faculty of Arts and Sciences, an appointment probably unique under that Faculty. From 1926 on he served also as Tutor in the Department of Mathematics. During the first world war he served in uniform in Washington, as Major on statistical duty for the General Staff. During the first half of 1925-26 he held what was known as the Exchange Professorship to the Western Colleges, and in the second half of the same year he attended, as delegate of the American Mathematical Society, a scientific congress in Lima, Peru, where he received the honorary Sc.D. degree from the University of San Marcos. After his retirement he was able, to his great gratification, to render valuable services during the second world war as Consultant in Research to the National Defense Research Committee on various confidential problems. In the last years of his life he waged with fortitude a foredoomed battle against the encroachments of paralysis agitans, supported by the devoted ministrations of his wife. He finally succumbed on November 25, 1952.

(This article is a re-publication of an article which appeared in the Harvard University Gazette. It was prepared by a committee consisting of Professors P. W. Bridgman, Chairman, W. V. Quine, J. H. Van Vleck, D. V. Widder, and was spread upon the records of the Harvard faculty in recognition of Professor Huntington.) 